\title{
Poesia ou Narciso à procura de si
}

\author{
Poetry or Narcissus' demand for himself
}

\author{
Emanuel Guerreiro ${ }^{1}$ \\ Faro, Portugal.
}

\begin{abstract}
Resumo: este estudo aborda a Poesia como arte da palavra, de comunicação divina e de expressão oral que transfigura simbolicamente a emoção e a vivência humanas. Ler-se-á a poesia moderna como experiência de alteridade, em que o sujeito poético recorre a um jogo de linguagem ao desdobrar-se entre o "eu" que fala e o "outro" que é representado, em uma perspectiva especular.

Palavras-chave: Poesia. Narciso. Linguagem. Voz. Alteridade.
\end{abstract}

Abstract: This study presents Poetry as an art of the word, divine communication and symbolically transfigured emotion and human experience. It will show the modern poetry as an experience of otherness, in which the poetic subject uses a language game, unfolding between the "I" who speaks and the "other" that is represented, like Narcissus in front of a mirror.

Keywords: Poetry. Narcissus. Language. Voice. Otherness.

"[...] arte da escrita, entre memória e invenção [...]" (Patrícia Leal, Buescu, 2008, p. 121)

"A Poesia é uma resposta, não é uma questão". (Eduardo Lourenço,1987, p. 70)

\section{Poesia}

Descoberta e libertação da palavra na busca da aproximação ao Belo, a Poesia é uma arte da linguagem: ela não diz, sugere. É uma reflexão sobre o mundo e sobre a experiência humana, é a realização de uma ideia em imagens simbólicas. É uma linguagem trabalhada, moldada, submetida à vontade do poeta, ao fazer da palavra criação do novo: de uma nova forma de dizer, de novas possibilidades de linguagem. A palavra "poesia" deriva do termo grego poiesis, que significa "fazer", “criar", “compor", e manifesta-se em uma ligação ao transcendente e no domínio da técnica de trabalhar a língua, o que remete para a capacidade da palavra poética na sua musicalidade, conotação e subjectividade. A palavra é o elemento material da poesia, realização da ideia dotada de valor poético através da linguagem figurada, expressão do que é pensado e sentido dito metaforicamente. A poesia é (re)criação da linguagem, ao envolver as palavras em sugestões e ritmos e transpor o pensamento em uma realização transfiguradora em expressão artística e experiência poética.

Ao evocar reminiscências orais e a dimensão de musicalidade, a poesia existe desde a mais longínqua antiguidade e reveste-se de um carácter sagrado de comunicação com os deuses, em uma ligação da poesia e da linguagem com origens míticas. Os oráculos eram manifestações em verso da palavra divina, revelações enigmáticas cujo efeito assentava em modulações rítmicas e em significados simbólicos. A linguagem da vidência e da profecia era, também, poética. Assim, a "primeira” poesia era uma linguagem sagrada, em que se reconhecia uma 
comunicação divina. Em uma componente simbólica e antropológica, oração e poesia juntam-se e ecoam entre si. Por remeter para o indizível, o poeta (designado como cantor ou vate) assume uma função demiúrgica, como um mediador em relação ao divino, dotado de uma aura mística ao comunicar através do ritmo e por associações simbólicas, ligado a um poder superior à esfera terrestre e receptor do sopro inspirador. A poesia serviria, então, como ligação ou mediação com a religião.

Muito antes de ser escrita, a poesia foi cantada, criação pelo ritmo, uma expressão popular e tradicional de carácter oral, que punha em relevo as propriedades fónico-estilísticas (como a aliteração e a rima), com apelo a recursos técnico-formais que determinam a sua relevância nos planos funcional e semântico ${ }^{2}$. Em poesia, é fundamental a relação entre som e sentido, pois é o ritmo que suporta o sentido e permite reter na memória a mensagem do texto poético. Daí que a transmissão oral da poesia seja essencial para exercitar a memória. A voz assume um papel determinante, como meio de expressão que a palavra do poeta reveste de força de acção, de poder de sedução, como forma de apelar e contaminar um auditório: a palavra contagia, chama, une. A poesia depende do canto e da oralidade; daí, afirmar-se o canto como metonímia da poesia, ao revelar a emoção do poeta, expressão da sua interioridade ${ }^{3}$.

Até meados do século XV, a poesia cultiva-se, sobretudo, oralmente e a sua transmissão faz-se com recurso à memória, dadas as qualidades formais (ritmo, rima, aliterações) que facilitam a memorização. Veja-se que, nesse tempo, poucos sabiam ler; daí que a palavra poética fosse pela voz, ouvida, pois a oralidade era valorizada pela expressividade e pela musicalidade dos ritmos ${ }^{4}$. Foi a partir do Renascimento, com a difusão das letras e a sua aprendizagem, que se começou a desenvolver a poesia mais na sua feição de leitura individual do que para ser escutada ${ }^{5}$. Nos séculos XVI e XVII, a poesia barroca apresentaria duas estéticas que se denominaram "conceptismo" e "cultismo". O conceptismo valorizava "o que dizer" e o significado da palavra, com jogos de raciocínio e de agudeza ou subtileza de pensamento; enquanto o cultismo valorizava "como dizer" (o som e a forma) e recorria a jogos de palavras, de imagens e de construção (alternância, simetria, paralelismo). Pode mesmo referir-se à elaboração de uma poesia visual que antecipa algumas experiências de vanguarda do século $\mathrm{XX}^{6}$.

O Romantismo investiria o poeta como sacerdote supremo de uma inspiração sagrada, revelador do conhecimento por ser dotado da capacidade de captar a linguagem da natureza, de uma expressão lírica que articulava o universo e o verbo poético na descoberta de afinidades, ao recorrer à metáfora e ao símbolo, em demanda da essência da poesia. Descobre-se a natureza e descobre-se o homem. Ao coincidir ser e linguagem, a expressão do poeta era de celebração, de que dava testemunho ao fazer da sua subjectividade fonte dessa elevação ${ }^{7}$. Heidegger identificava a poesia com a revelação ou verdade do Ser - à Poesia competia a fundação do Ser pela palavra. Movida pelos ideais românticos, a poesia simbolista revela-se no apelo à subjectividade e à

\footnotetext{
2 Declara Luís Quintais (2018, p. 58): "O que propõe a mão quando escreve?/O funâmbulo sentido da fala".

3 Considera Maria Vitalina Leal de Matos (2001, p. 287): "O verbo poético nunca se pode divorciar (sob pena de entrar em declínio) da sua condição intrinsecamente musical, rítmica.".

4 Recordem-se os cancioneiros medievais, que incluem o poema e a pauta com a música que o acompanhava. Ou na Antiga Grécia: lírica era a poesia mais emotiva e expressiva que se destinava a ser cantada ou acompanhada à lira.

5 “Ler em voz alta era designado por 'recitare' e, até ao final da Idade Média, a leitura consistirá numa enunciação em voz alta, qual recitação. Leitura partilhada, teatral, o texto era dito; logo, ler era uma aptidão oral. Há que atender, também, ao reduzido número de pessoas que sabia ler, fazendo-o para um grupo não possuidor dessa capacidade, instruindo e distraindo, e que, só após a invenção da imprensa, a produção de livros aumentou, permitindo que crescesse o número dos seus possuidores e de leitores”. Cf. GUERREIRO, 2015 , p. 151. 6 Cf. os estudos que a Professora Ana Hatherly dedicou profusamente ao Barroco, em obras como, por exemplo, A Experiência do Prodígio - Bases Teóricas e Antologia de Textos Visuais Portugueses Dos Séculos XVII e XVIII, IN-CM, 1983.

7 "Nesse movimento expressivo, ao dizer a partir de si, a partir da linguagem que a sua particular entrega faz ressoar, o sujeito lírico poderá alcançar uma formulação, um ritmo, uma imagem que, repetidos por outros, lhes sirvam para recordar o seu autor e para confundir os sentimentos deles com o seu”. Cf. MATOS, 2001, p. 299.
} 
musicalidade, no uso de figuras de som e de linguagem: "De la musique avant toute chose...", defenderia Paul Verlaine. Ao acreditar que a arte devia captar a verdade mais absoluta, os simbolistas exaltavam a realidade subjectiva, a valorização do "eu" e da imaginação, ao buscar compreender a diversidade da alma humana através de uma linguagem expressiva e da versificação livre, desdenhando a objectividade na aproximação entre poesia e música.

Com Fernando Pessoa, e o advento do Modernismo, a poesia portuguesa assume uma intelectualização das emoções (a poesia deriva de uma construção mental que filtra a emoção ao passá-la para o texto - a criação poética resulta da interacção razão/sentimento), ${ }^{8}$ uma capacidade reflexiva que o pós-modernismo põe em relevo em jogos de linguagem, uma reflexão sobre a criação e um trabalho sobre a matéria verbal que a transforma em experimentação do sentido.

\section{Criação Poética}

Por que razão escreve o poeta? De onde vem a sua inspiração? O que são as palavras, quais os seus limites? O discurso poético está imbuído de um pendor subjectivo e põe em relevo as potencialidades rítmicas e melódicas das palavras. O poema é a "voz" do poeta, que se define e representa numa primeira pessoa pronominal e reflecte sobre a experiência da percepção do mundo e de si próprio. A relação que o poema estabelece com o leitor é dialógica, através da pressuposição de um interlocutor na segunda pessoa. ${ }^{9}$ O leitor é, então, uma figura necessária, capaz de conferir uma "presença real" ao sujeito poético, entidade fictícia e egocêntrica que se constitui no processo de interiorização, mas que se distingue do autor empírico.

O poema define-se a partir de sensações, emoções, ideias, imagens e constrói-se com base em atributos fónico-linguísticos, em procedimentos de redundância fónica, em um processo em que a similaridade rítmica e o paralelismo de ritmos evidenciam a motivação semântica. A utilização de recursos como a aliteração, a rima, o ritmo ou o metro, surgem investidos de um poder de sugestão; trata-se de transfigurar uma ideia em imagem, com recurso a repetições fónicas, jogos musicais e estruturas rítmicas, elementos a que o poeta recorre como condição do seu fazer poético. A imagem poética é, então, a introdução de um sentido metafórico, em analogia simbólica.

A metáfora desempenha um papel nuclear na poesia através de analogias, processo em que o jogo de semelhança implica uma nova designação do mundo ao deslocar a referência da imitação para a imaginação criadora. A metáfora exige um contexto duplo: o de uma realidade, que se refere ao sujeito, e outro plano, em que um elemento desse real ganha outra designação. Trata-se de uma capacidade de criar significado(s), o que implica a compreensão do jogo metafórico. Tal significa compreender que um objecto ou uma realidade podem ser descritos de forma simbólica, através de um trabalho de singularização na representação de imagens e conceitos. A metáfora é, pois, o princípio fundamental da criação poética: a possibilidade de multiplicar sentidos, leituras, interpretações, que faz do texto poético um espaço de permanente abertura à imaginação e ao inesperado, ao permitir uma outra forma de perceber e representar as relações com o mundo.

A poesia não é uma arte fixa, rígida, fechada; pelo contrário, ela apresenta o que existe de pessoal em cada indivíduo. Ao procurar a comunicação e exprimir o seu mundo interior, o poeta revela-se, à sua alma e ao seu tempo. O poema nomeia o mundo, "um mundo", trazido à letra pela palavra poética. A linguagem descreve o mundo e a linguagem verbal, expressa de forma poética, mediante o poder criador e transfigurador da poesia, permite a criação de mundos dentro e através da linguagem ${ }^{10}$. Assim, o poema é produtor da sua percepção estética: a poesia implica

8 “[...] um poema [...] não é mais que uma carne de emoção cobrindo um esqueleto de raciocínio [...]”... Cf. FERNANDO PESSOA, 2006, p. 16.

9 Evoquem-se textos como a autobiografia e o diário, onde sujeito e objecto confluem, o que permite ao autor ver-se a si mesmo, num exercício de alteridade em que se expõe, num diálogo entre quem escreve e se descreve.

10 "Tudo é linguagem. A dor é dor reescrita". Cf. QUINTAIS, 2018, p. 68. 
uma articulação dialógica do seu discurso, muitas vezes como interpelação a um outro cujo espaço o leitor tenta, ou é solicitado, a ocupar. O contacto dialógico implica a presença do interlocutor suposto, pelo que o verbo que melhor traduzirá a faculdade que a poesia consente seria o verbo "sentir" (como verbalização ou expressão da interioridade) e já Fernando Pessoa (1992, p. 236) reflectira sobre esta ideia ao afirmar: "Sentir? Sinta quem lê!".

O poema manifesta-se como espaço onde o homem, ser múltiplo em constante transformação, permanece na memória da palavra, que evoca a identidade do eu e a experiência do ser no tempo. A sua capacidade de criar deriva da memória, como participação e relação com o passado, a que se alia a imaginação no processo de criação ${ }^{11}$. É a imaginação o motor da produção poética, do possível, força que determina o indivíduo a existir no que escreve e pelo que escreve, por exprimir um conteúdo interior, psicológico, sentimental, ou representar um exterior perante si. Por um acto de libertação, o poeta nasce no poema, lugar, também, do nascimento do (seu) mundo. Aí, reside o fascínio e a atracção da imagem, condição do "eu" se afirmar como consciência criadora, como centro organizador, ao assumir o fazer poético como jogo e visão do enigma a desvendar, ou que pede para ser desvendado na, ou pela, leitura ${ }^{12}$. A experiência da leitura será o dom da partilha dessa visão. Reside, aqui, um processo de transfiguração: as imagens literárias resultam de uma substituição do literal pelo figurado e evocam o poder de representação. A relação entre o sentido próprio, ou literal, e o sentido figurado supõe a capacidade de ver e de reconhecer imagens e conceitos. As imagens têm a possibilidade de transportar para o leitor a decifração da energia criadora, ao interpretarem a emoção original. Entre a tensão e o equilíbrio da expressão emocional e a compreensão intelectual do poema, o sentido é partilhado e convocado no acto de leitura e resulta na aparição de uma visão poética através da construção de imagens, em um laço que une o poeta e o leitor, em um espaço de apropriação da linguagem figurada.

A memória é invenção, interpretação do vivido; é uma operação de trabalhar as imagens através da capacidade criadora da ilusão. Esta força de criação poética manifesta-se na expressão convocada pela escrita para se converter em revelação. Eis, pois, o desígnio da escrita poética: a intensidade libertadora do mundo do poeta, transposição do devaneio e da palavra em uma evocação de ritmos e visões. No acto criador do poema, o poeta constrói-se a si mesmo, pertence ao poema como dom de existência que atribui a si próprio, ao persistir, em potência, no seu texto ${ }^{13}$. É pelo acto de ler que o leitor acede a essa presença, por despertar a figura do autor e estabelecer o diálogo que motivou a leitura. Ela apela ao desvendamento e estabelece uma relação de complementaridade em que ambas as figuras precisam da outra para o nascimento da palavra.

\section{Poesia Moderna}

A poesia moderna coloca ao leitor um desafio de compreensão, dado procurar um vocabulário ou um uso expressivo que se afasta da forma comum de pensar e exprimir. Hermetismo? Texto fechado sobre si? Fala consigo ou para si mesmo? Considera António Ramos Rosa (1986, p. 30): "O poema essencialmente fala de si mesmo, isto é, do acto de criar, dessa experiência única em que se manifesta a liberdade humana fundamental.”. E acrescenta (1986, p. 50): “O poema só pode ser entendido a partir de si mesmo, porque em si mesmo se origina e o seu fim é ele próprio" ${ }^{14}$.

\footnotetext{
11 Para Rui Nunes (2018, p. :63), “o passado descobre-me, não me inventa, [...] o passado é [...]”.

12 "lê-se para atingir uma totalidade qualquer, para descobrir o sentido, o grande sentido de um texto [...]". Cf. NUNES, 2018 , p. 75.

13 “[...] o poeta não existe senão pelo poema, pois não existe um estado poético prévio ou permanente: é o próprio poema que o eleva à condição poética, que o faz poeta”. Cf. ROSA, 1986, p. 32.

14 Considera Salvato Telles de Menezes (1993, p. 47) que “[...] grande parte da poesia contemporânea parece difícil porque poucos leitores lêem poesia enquanto tal, por quererem entendê-la sem lhe dedicarem a atenção que ela exige. [...] o poeta contemporâneo necessita da colaboração intelectual do leitor, porque a sua poesia sugere, recusa-se a declarar [...”. Há que atender, também, ao uso investido em procedimentos como o símbolo, a imagem e a linguagem figurada.
} 
Dois poetas, entre outros, se impõem quando nos referimos ao que se designa por "modernidade poética”: Charles Baudelaire (1821-1867) e Arthur Rimbaud (1854-1891).

Baudelaire é considerado como um dos pioneiros da modernidade poética por defender a liberdade de criação em relação a normas ou convenções literárias e exaltar a arte como expressão da vida, em uma busca por cortar as amarras da arte de qualquer vínculo que restrinja o poeta e abandonar o sentimentalismo romântico. A Baudelaire se atribui a ideia de a poesia suscitar novos modos de leitura do mundo, mesmo que os elementos poetizados causem choque, ao explorar o inesperado para o sentido da obra e a formulação da problemática da subjetividade na poesia moderna: na poesia de Baudelaire, lemos a afirmação do eu e o seu posicionamento face a um outro.

Rimbaud explorou essa ideia ao declarar o que tornar-se-ia o lema da modernidade, em uma afirmação poética revolucionária: "JE est un autre"15 Ao defender uma poética da alteridade, Rimbaud pensa a arte a partir de si própria e permite que se leia a sua declaração como uma formulação em que a antítese do "mesmo" e do "outro" pode ter como resultado uma unidade. A alteridade define-se em função de um pólo de referência, em que o "outro" não passa sem o "um". Não há alteridade sem ipseidade, como, posteriormente, defenderá Paul Ricoeur (1913-2005), ao pensar a existência de um sujeito no que faz com que seja ele próprio e não outro, individualizando-o de forma única ${ }^{16}$.

O pensamento da diferença, na expressão da alteridade poética, reside em uma tensão entre o "mesmo" e o "outro" como pertença mútua da identidade e da diferença, em uma "relação de alteridade" na qual o "mesmo" e o "outro" deixariam de excluir-se para incluir-se mutuamente. Estamos, poeticamente, a falar do funcionamento da linguagem na constituição do (seu) sujeito, na elaboração da poesia como "uma outra palavra". É o confronto com o "outro" da linguagem que leva o poeta a reinventar a língua, ao fazer ouvir, com a mesma língua, uma outra palavra. Assim, na modernidade, o próprio "eu" revela-se "outro(s)", sem deixar de ser o que e quem é.

Poder-se-á falar de uma cisão interna que permite à linguagem afirmar a (sua) identidade: entre o poeta e o seu discurso constitui-se uma relação complexa de referência e diferença, um diferendo íntimo que Rimbaud resumiu perfeitamente na formulação acima já citada. Essa fórmula, ao mesmo tempo que recusa o esquema tradicional da expressão poética, rejeitará a identificação do sujeito da escrita a uma limitação de simples efeito de linguagem. Nos jogos de linguagem, o "eu" coloca-se em questão e descobre-se "outro". O trabalho do poeta consistiria, pois, em apropriar-se dessa alteridade, reconhecê-la e cultivá-la como possibilidade, como conhecimento de si na sua completude, assim como na sua diversidade. O funcionamento da linguagem tornar-se-á, pois, um meio de conhecimento e de constituição de si, ao integrar no "eu" este "outro" que se afirma através da palavra, em uma implicação recíproca entre ambos. Se o "eu" reconhece no seu discurso uma polissemia, o poeta deixa-o falar através da linguagem, para afirmar-se como "eu" nessa alteridade irredutível.

É esta relação entre identidade e alteridade que funda a palavra poética moderna, na expressão de um "eu" desconhecido que é "outro", e que permite que o poema possa falar a nós, outros. Assim, o leitor pode tornar sua a palavra do poeta, dado esse parecer dirigir-se a ele. Com efeito, o poeta recorre ao uso da segunda pessoa para falar de si mesmo, como se não pudesse dizer "eu" sem se tratar por "tu”. Essa eventual confusão entre os papéis de locutor e interlocutor é um aspecto essencial do diálogo entre o "mesmo" e o "outro".

Para António Carlos Cortez (2004, p. 12), a poesia moderna visa a "[...] fundação de uma poética

15 Cf. Carta a Paul Démeny, de 15 de Maio de 1871, também conhecida pela designação de «A carta do vidente». Tradução de Leo Gonçalves. Disponível em: http://www.salamalandro.redezero.org/wp-content/uploads/2007/07/Rimbaud-A-carta-do-vidente-Lettre-a\%CC\%80Paul-De\%CC\%81meny.pdf. Acesso: 19 de Agosto de 2019.

16 O conceito de ipseidade, de Paul Ricoeur, reveste-se de um carácter reflexivo, em que o «eu» se designa a si próprio não só como semelhante a outro, mas a si-mesmo considerado como outro, com a possibilidade de se experienciar como outro, "eu" que sofre mudanças por acção temporal e que se transforma em outro. 
centrada na perseguição de um sentido da palavra”. Fruto de uma metamorfose, a palavra comum sofre uma eclosão de energia, uma libertação que a converte, poeticamente, noutra significação. Essa metamorfose inaugural regenera a palavra da linguagem comum em uma participação criativa e inventiva que a instaura de uma potência verbal. A palavra da linguagem comum torna-se "outra", ganha uma nova dimensão, mas não independente da linguagem que a formula e que cria uma nova realidade. A palavra é figura da relação que o sujeito estabelece com a linguagem, ao fundá-la e nela se fundar. Dá-lhe o ser e por ela, por esse acto, torna-se parte desse ser. É neste acto criador que se revela a aparição do sentido da palavra. A poesia moderna será, então, dotada de alteridade: a palavra torna-se outra, poeticamente, em um princípio de liberdade criadora e de permanente renovação. Nesse acto de dar um "novo sentido", o poema caminha para uma multiplicação de perspectivas de leitura ${ }^{17}$.

A poesia moderna tem, pois, a alteridade como uma das suas características principais: "Se a poesia moderna é uma experiência da palavra, é, também, concomitantemente, uma experiência da realidade. [...] É assim que o poeta reconhece o outro em si [...]" (ROSA, 1991, p. 19). Podemos encontrar, na poesia moderna, uma situação existencial de instabilidade que torna o poema um lugar de incerteza e de interrogação. A procura da identidade transforma-se em uma busca do outro, que é procura de si mesmo. Vemos Narciso apaixonado pelo seu reflexo, onde se vê não a si próprio, mas "outro", como "outro", e é esse "outro" que é desejado ${ }^{18}$. A ideia de que o sujeito não está só quando se vê ao espelho revela uma articulação entre o "eu" e o "outro", postulado dicotómico que tende a fragmentar o sujeito; daí, a elaboração de um discurso que procura encontrar a percepção de "si" na categoria do "outro".
A leitura pode ser entendida a partir do conceito de alteridade, ao ver o poema como lugar de ausência, mas, igualmente, lugar de presença: o poeta oculta-se, mas o acto de ler estabelece a relação com o leitor, que desperta a sua marca deixada no poema e descobre o autor que (se) escreve através de estratégias de composição ficcionais. A alteridade poética leva(-nos) a pensar na co-pertença, como se a criação participasse, simultaneamente, do "mesmo" e do "outro", como se "um" não se dissociasse do "outro". Ser, simultaneamente, identidade e diferença, esta separação íntima entre $o$ "mesmo" e o "outro" como paradoxo, resolve-se em uma relação de alteridade. Mais do que reduzir "um" ao "outro" os termos da relação, deve-se é interrogar a interacção entre eles, tentar compreender de que forma, nos jogos de linguagem, o "eu" se posiciona e se relaciona com o "outro". "Eu é um outro" revela a descoberta do eu como outro, ao rejeitar a concepção cartesiana que dava ao sujeito a faculdade de coincidir consigo mesmo no acto de pensar. O que o poeta diz (ou o "poeta diz") visa afirmar-se como "eu” em uma relação íntima com a alteridade, com esse desconhecido que ele traz em si próprio. É esse nó entre identidade e alteridade que funda a palavra poética, que faz com que o poeta possa falar por ela e que o leitor possa responder-lhe. $\mathrm{Na}$ medida em que o poeta revela um "eu" desconhecido, que é "outro", o poema fala ao leitor, que é "outro". Trata-se, afinal, de um diálogo entre $o$ "mesmo" e o "outro", que ressoa na experiência poética, convertendo o "eu" em "tu".

Leia-se o seguinte excerto de um poema de valter hugo mãe (2008, p. 13):
deixa-me perguntar se te pareço tão assustado assim. não me sinto deslocado, talvez curioso, mas nem surpreso. algo em ti me puxa sempre ao sentimento, mesmo antes de

\footnotetext{
17 "É a grande aventura da poesia moderna que se inicia, é um novo conceito estético que se forma: o da obra susceptível de se enriquecer progressivamente, apontando a mil direcções, ganhando a cada leitura novos significados [...]”. Cf. ROSA, 1986, p. 46.

18 "[...] a imagem de Narciso e o seu complexo estão sempre ligados ao acto poético, o sujeito interroga-se constantemente sobre o seu estatuto, sobre a origem do seu discurso e sobre a distância que ele pressente existir entre si e os outros ou entre si e o tu que ele pretende atingir na busca de uma identidade que continuamente lhe foge e que insistentemente procura”. Cf. MARINHO, 1989, p. 70.
} 
te tconhecer, lembras-te, uma propensão para te tratar bem, cuidar, vulnerabilizar os meus modos, recusar admitir que, também eu, sou capaz de crueldades quotidianas e impunes.

Há um "diálogo" entre o sujeito e um "tu", expresso nas formas verbais e pronominais: o lugar ocupado pelo sujeito da enunciação é partilhado com um "tu", ambos ficcionados como personagens numa micro-narrativa que expõe a negatividade da não relação ou do fracasso da relação com o outro, da dificuldade de uma relação afectiva com o outro, na tentativa de reconstituição dos momentos vividos e na busca de sentido desses momentos. Ouvimos a voz do sujeito, em uma expressão que pode remeter para um frente a frente, face a face com outro, ou consigo mesmo. A alteridade está presente em uma referência dialógica que procura abranger o outro em um laço de pertença, ao denunciar as marcas do sujeito na vulnerabilidade, oralidade, coloquialidade, confidência, solicitação de resposta ao outro, de confirmação, de comunicação estabelecida, de laços que se criam, cumprem e mantêm ao evocar a substância afectiva do que se perdeu e é presentificado poeticamente. O sujeito fala de si mesmo dado que o outro impõe a sua ausência, o "tu" é uma criação do sujeito, a sua presença existe apenas no discurso, só existe no universo da mensagem poética. Mas podemos ler esse "diálogo" como se se processasse do sujeito consigo mesmo, como autoanálise que questiona as vivências com o outro, pondo-se em causa ao interrogar-se sobre a sua forma de actuar. Assim, falar-se-ia de um estilhaçamento da identidade pessoal apresentado a partir de uma experiência comum, ficcionável em uma linguagem muito próxima do registo coloquial, inscrita em um ritmo poético. Ler-se-ia, então, o sujeito face a si mesmo, julgando-se na sua conduta, como se, em um espelho, se visse a actuar e dirigisse a si próprio uma apreciação que avalia os seus actos.

O "outro" é elemento constitutivo do mundo do "eu" e o modo de formulação a que o sujeito recorre é o discurso da alteridade que implica, em termos discursivos, um sujeito desdobrado e a introdução de um outro ficcional. A alteridade implica um pendor dialéctico na relação "eu-tu" e é necessário que o "eu" literário se torne um "tu" para o sujeito se poder representar como "outro". É o excesso da presença do outro que leva o sujeito a voltar-se para si. Ao recorrer à encenação, o campo do "outro" passa a ser representação do "eu" em uma projecção especular como marca do outro presente/ausente, que é, afinal, um "outro eu" do sujeito, ao mesmo tempo destinador e destinatário que evidencia a dimensão dialógica do discurso interior (leia-se um ouvinte virtual, potencial). A ficção permite a duplicação: através da encenação, o indivíduo duplica-se, encena-se a diferença, o que pode significar autoconhecimento. Existe uma alteridade intrínseca que provoca o desejo de autorepresentação e de autoexploração e é esse desejo que origina a necessidade de, ou da, ficção.

Perante o espelho, o sujeito sucumbe, narcisicamente, à ilusão da unidade: há um vazio perceptual e emocional na experiência do espelho que se dirige à carência do outro, dado existir uma reciprocidade entre a formação do sujeito e o olhar do outro. O que significa encontrar-se a si mesmo no lado de fora, em uma tensão de semelhança e de diferença, na qual o sujeito se encontra a si mesmo no limite de transformar o outro em um "eu-outro". A identidade subjectiva do texto lírico é fruto da sua própria natureza, sendo produzida nele e por ele, através da linguagem, em que a capacidade de ver-se de fora, de ler-se como um outro parece condição primordial.

\section{Voz Poética}

Qual é, então, a voz que fala no poema? Essa voz constrói-se na e pela linguagem, que rege a enunciação lírica a partir do "eu”. De novo, é a ideia de alteridade, de desdobramento tanto referencial quanto subjectivo que entra em jogo, um exercício da linguagem como meio indispensável para a existência do poema. A alteridade ganha um carácter dialógico, tendo em vista o seu valor de resposta: é em um jogo entre $o$ "mesmo" e o "outro" que se situa a poesia, em um exercício de desdobramento, de busca, pela 
linguagem, pela construção da subjectividade, pela representação do mundo, entre o poeta criador e o sujeito poético que se expressa e fala no poema. Há, pois, sempre um exercício de alteridade na construção de um poema: dada a natureza específica do texto lírico, a identidade do sujeito deriva, por um lado, de uma determinada visão de mundo expressa pela linguagem e, por outro, de uma determinada forma de enunciar essa visão. Apreendemos o mundo, isto é, um modo de construir as imagens do mundo, através da linguagem e, como elemento textual, o sujeito é sempre uma "ficção" que deve a sua existência ao texto, pelo que só se pode procurá-lo no próprio texto.

Assim, “[...] a poesia moderna não pode ser interpretada mediante categorias que não têm em conta a sua alteridade irredutível" (ROSA, 1991, p. 24). É no acto de criação poética que o "eu" se constitui e (auto)constrói, tal como a sua relação com o(s) outro(s). A linguagem poética oculta, mas também revela e é nesse jogo de sombras ou espelhos que o sujeito se descentra e multiplica a visão de si, do outro e de si como outro. Como mediadora entre a imaginação do poeta e o mundo, a palavra poética permite a tomada de consciência da expressão do sujeito e que o distancia ou aproxima do mundo e do(s) outro(s). Na aproximação de si mesmo, ou na relação com o acto de criar que o poeta empreende, o sujeito toma consciência do poder criador que projecta uma revelação luminosa, em busca da descoberta que a linguagem, como espelho imediato, reflecte como lugar de identidade. A palavra poética, por assumir um sentido de diferença ou do que é novo, ao criar uma (nova) realidade ou o que não foi dito antes, adopta uma qualidade inaugural ou de nomeação, na (re)descoberta e interrogação. É ao interrogar-se, ao pôr(-se) em questão, que o poeta molda o poema como experiência de linguagem que valoriza a metáfora; isto é, um momento de abertura, de desvendamento, de conhecimento ou representação de uma relação não unívoca entre as palavras e as coisas. Como referência fundamental para a compreensão do jogo poético e por evocar o indizível, a palavra poética não tem "um sentido", não é literal, mas sim dotada de uma transfiguração que a torna lugar de outra(s) voz(es) e de testemunho, memória, lugar de invenção e de interrogação da experiência poética.

Como Narciso face à superfície espelhada, que interroga (e se interroga sobre) a (sua) imagem, a poesia faz-se da alteridade e da singular diferença, da reflexão sobre, ou da linguagem como encontro do sujeito poético com outro a quem se dirige, criado como desdobramento ou outra versão de si a quem faz falar. Entre "ser eu" ou "ser outro", entre a primeira ou a segunda pessoas, o sujeito assume uma característica "dramática”, em uma dualidade "eu-outro" que enforma o acto criador ${ }^{19}$. Sendo o mundo subjectivo a matéria primacial do poema, é necessária uma voz pessoal onde o poeta projecta o (seu) "eu" e que adquire um estatuto de "outro". Um "outro" na voz do poeta, ou uma "outra voz", expressão de uma alteridade, uma experiência de linguagem pela qual o sujeito age sobre o mundo e sobre si próprio. Assim, a poesia consegue dizer, consegue revelar, é a procura da palavra pela qual o sujeito expressa a sua emoção e permite-lhe uma fala de um "eu fictício", "fendido", que se olha para si mesmo e que se encontra com outro(s) ou cujo discurso pode ser apropriado por outro(s).

A voz poética expressa-se através da linguagem e da memória, ambas criadoras de mundos e invenção de sentido(s) que fazem o poema nascer entre a palavra e o silêncio. Mas é no indizível que a escrita de poesia se debate em uma abertura à sua indeterminação. Considera Fernando Guimarães (1997, p. 73):

\section{[...] Keats afirma que "um poeta é o ser menos poético que existe, porque não possui nenhuma identidade", isto é, não equivale a uma presença poética com a qual se possa identificar dado que essa presença só poderia ser a do poema.}

É o poema que é dotado de força criadora, gerador de uma singularidade de linguagem entre a

“[...] o poeta é não ele mas uma sua 'personagem' e [...] o 'eu' e o 'tu' poéticos são figuras 'teatrais' e a poesia toda ela 'dramática': teatro da Alteridade [...]”. Cf. DIAS, 2014, p. 44 
identidade e a diferença, investido da inspiração que permite o acesso à visão de "outro mundo", proposta de um encontro com o absoluto e do poeta consigo mesmo. O poema é auto-referencial, em uma aprendizagem de nomeação: "Um texto diante do espelho: vendo-se, pensando-se" (OLIVEIRA, 1995, p. 206). Como Narciso, qual Narciso.

\section{Referências}

CORTEZ, António Carlos. Nos Passos da Poesia. Lisboa: Apenas Livros, 2004.

DIAS, Sousa. O que é Poesia?. Lisboa: Sistema Solar (Documenta), 2014.

GUERREIRO, Emanuel. Sobre a Leitura. Revista Decifrar, Manaus, v. 3, n. 6, p. 150-162, jul./dez. 2015.

GUIMARÃES, Fernando. Conceito, figura e conhecimento. In: HATHERLY, Ana; LOPES, Silvina Rodrigues (org.). Os Sentidos e o Sentido: literatura e cultura portuguesa em debate. Homenageando Jacinto do Prado Coelho. Lisboa: Edições Cosmos, 1997. p. 73-76.

LEAL, Patrícia. Migrações do humano: Poesia e multitude. In: BUESCU, Helena Carvalhão e Kelly Benoudis Basílio (org.). Poesia e Arte. A Arte da Poesia. Homenagem a Manuel Gusmão. Lisboa: Editorial Caminho, 2008. p. 117-134. https:// doi.org/10.1353/sir.0.0030

LOURENÇO, Eduardo. Tempo e Poesia. Lisboa: Relógio d'Água, 1987.

MÃE, Valter Hugo. Folclore íntimo: poesia reunida. Maia: Cosmorama Edições, 2008.

MARINHO, Maria de Fátima. Do eu ao outro: euforia e disforia. In: MARINHO, Maria de Fátima. A Poesia Portuguesa nos meados do século $X X$ : rupturas e continuidades. Lisboa: Editorial Caminho, 1989. p. 69-96.

MATOS, Maria Vitalina Leal de. Introdução aos Estudos Literários. Lisboa/ São Paulo: Editorial Verbo, 2001.

MENEZES, Salvato Telles de. O que é Literatura. Lisboa: Difusão Cultural, 1993.

NUNES, Rui. Suíte e Fúria. Lisboa: Relógio d’Água Editores, 2018. OLIVEIRA, Carlos de. O Aprendiz de Feiticeiro. 4. ed. Lisboa: Livraria Sá da Costa, 1995.

PESSOA, Fernando. Poesias. 8. ed. Lisboa: Edições Ática, 1992.

PESSOA, Fernando. O Caso Mental Português. In: PESSOA, Fernando. O Provincianismo Português. Lisboa: Editorial Nova Ática, 2006. p. 9-16.

QUINTAIS, Luís. Agon. Lisboa: Assírio \& Alvim., 2018.

ROSA, António Ramos. Poesia, Liberdade Livre. Lisboa: Ulmeiro, 1986.
ROSA, António Ramos. A Parede Azul: estudos sobre poesia e artes plásticas. Lisboa: Editorial Caminho, 1991.

\section{Recebido em: 17/4/2019.}

Aprovado em: 20/6/2019.

\#33936

SEÇÃO: ENSAIOS

\section{Emanuel Guerreiro}

(sem vínculo institucional)

Orcid: https://orcid.org/0000-0002-6849-8584

E-mail: emanuel-guerreiro@hotmail.com

Endereço de correspondência: Rua Ataíde de Oliveira n. ${ }^{\circ} 40-3 .^{\circ}$ esquerdo. 8000-223 Faro - Portugal 